\title{
Simulation of Heat Transfer in Primary Heat Exchanger of ACS with Variable Finnings
}

\author{
A.V. Chichindaev \\ Department of Technical Thermophysics \\ Novosibirsk State Technical University \\ Novosibirsk, RUSSIA \\ e-mail: ttf_nstu@rambler.ru
}

\author{
I.G. Diomidov \\ DuPont Science and Technology Ltd. \\ Moscow, RUSSIA \\ e-mail: diomidovs@yahoo.com
}

\author{
Y.V. Dyachenko \\ Department of Technical Thermophysics \\ Novosibirsk State Technical University \\ Novosibirsk, RUSSIA \\ e-mail: ttf_nstu@rambler.ru
}

\begin{abstract}
Compact plate-fin heat exchangers are extensively used in automotive, marine and aviation industries. The thermal stress in structure of heat exchange surfaces is sufficient and leads to reduction of the resource of such devices if they are used for cooling hot air $\left(300 \ldots 600{ }^{\circ} \mathrm{C}\right)$. The utilization of the approach considers the variable ratio of the thermal resistance between hot and cold sides of the heat transfer surface for design of plate-fin heat exchangers, which is one of the potential prospective ways to reduce the thermal stress in the structure. The results of numerical experiments based on the mentioned approach for the modeling of pre cooler for the aviation air conditioning systems (ACS) are presented in the article. In the present study the authors established the basic appropriateness and proposed the most optimum options for design to sharply reduce the thermal stress in the structure of plate-fin heat exchangers.
\end{abstract}

Keywords- heat exchangers; thermal stress; thermal resistances

\section{INTRODUCTION}

The primary heat exchanger of the aviation air conditioning system (ACS) is the most thermally loaded heat exchanger with a low service life [1]. It is installed on the engine of the aircraft at the point where air is bleeding to the ACS (Fig. 1). At the heart of its operational problems there is a large temperature difference between the heat carriers. In hot air it can reach $400 \ldots 600{ }^{\circ} \mathrm{C}$, while in cold air it is $-50 \ldots 0{ }^{\circ} \mathrm{C}$. Multiple heating and cooling of the primary heat exchanger in the "parking - cruising flight - parking" cycle leads to a decrease in strength properties of the construction material. The main reason is the phenomenon of low cycle fatigue strength [2] when the heat exchanger structure is destroyed after 1000 cycles. After that, hot and cold heat carriers flow into the technical compartments of the aircraft.

A compact plate-fin heat exchanger is a structure in which the hot and cold heat carriers (fluids) are separated by a flat plate, and channels for heat carriers are formed by flat or ruffled fins. The parallel channels for heat carriers (fluids) are connected together by manifold blocks. The sketch of such heat exchanger is shown in Fig. 2.

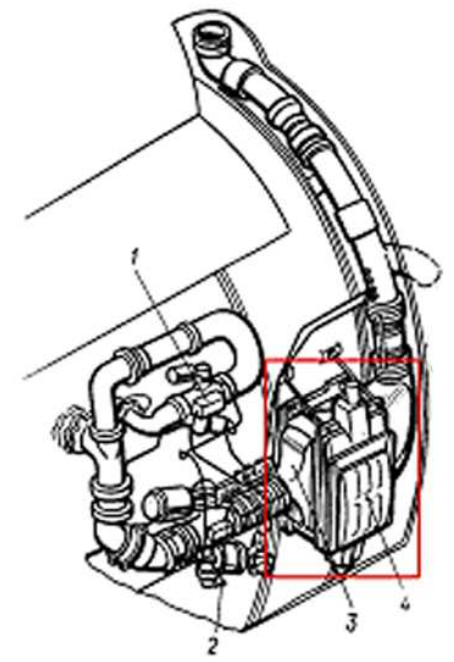

Fig. 1. Placement of the primary heat exchanger on the aircraft engine: 1 pressure regulator, 2 - flow controller, 3 - hot air inlet, 4 - primary heat exchanger

A distinctive feature is the cross-flow scheme of the flow of heat carriers. It leads to the appearance of large temperature drops of the heat exchange surface up to $300 \ldots 400{ }^{\circ} \mathrm{C}$. This in turn generates high equivalent thermal stresses. Traditional ways to increase the strength and reliability of the compact plate-fin heat exchanger design are associated with the use of stronger materials (high-alloy heat-resistant steel) or with the use of additional structural elements, which leads to a significant increase in the cost and / or mass of the unit. 
Heat exchangers designed according to traditional methods (V.M. Kays, A.L. London [3], G.I. Voronin [4]) have parameters that are different from optimal ones, because the integral calculation and design technique does not take into account the features of the local distribution of temperatures. In later works, (E.K. Kalinin, G.A. Dreitzer, G.I. Voronin, E.V. Dubrovsky, G.A. Dreitzer, A.C. Myakochin [5,6]) the main attention was directed to the development of new types of finned surfaces with maximum thermal efficiency and minimum dimensions and weight. In the publications for higher educational institutions it is indicated that there are operational problems, but there are no recommendations for their solution $[7,8]$.

In work [9], an approach to designing and optimizing the primary based on control of local values of the temperature of the heat exchange surface due to changes in the parameters of fins and modes of flow of heat carriers is proposed.

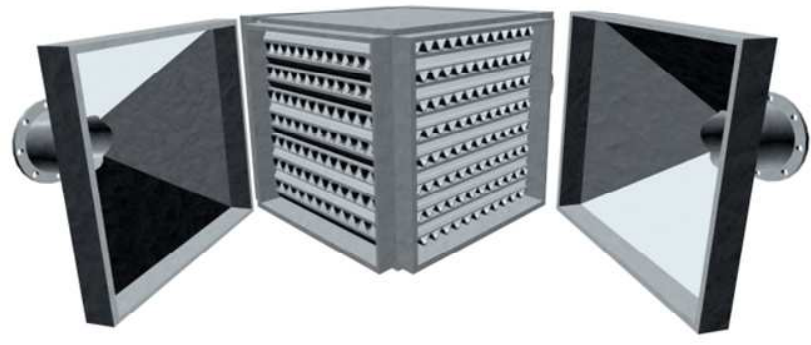

Fig. 2. The sketch of the plate-fin heat exchanger

The main factor affecting the magnitude of thermal stresses in the structure of the heat exchanger is the distribution of temperature in the structure. The more evenly distributed temperature, the less levels of thermal stresses in the structure. One of the promising ways of increasing the resource of compact heat exchangers is the use of variable thermal resistance along the length of cold and hot channels for a more uniform temperature distribution on the heat exchanger structure [10].

Initial studies of compact heat exchangers with a variable ratio of thermal resistances showed high efficiency of this approach in reduction of the thermal stresses in the structure of compact plate-fin exchangers [10]. However, the obtained results are limited due to the small range of the values of the variable ratio of thermal resistance that have been considered.

The purpose of the present work was to develop a refined method of calculation and to study the impact of the variable ratio of thermal resistances on the process of heat transfer and thermal stresses in the compact plate-fin heat exchanger.

\section{COMPUTATIONAL PROCEDURE}

\section{A. Problem Definition}

The temperature of heat transfer surface is determined by the thermal resistance, which, in general, is defined as (1):

$$
R=R_{1}+R_{2}+R_{3}=\frac{1}{\alpha_{1} F_{1}}+\frac{1}{\alpha_{2} F_{2}}+\frac{\delta}{\lambda F_{1}} .
$$

Here $R_{1}, R_{2}$ is the thermal resistance of heat transfer processes between the fluids and the wall; $R_{3}$ is thermal resistance of heat conductivity through the wall.

The ratio of thermal resistance of cold and hot channels $R R$ is a convenient generalized criterion (2):

$$
R R=\frac{R_{2}}{R_{1}}=\frac{\operatorname{Re}_{1} \varphi_{1}}{\operatorname{Re}_{2} \varphi_{2}}=\frac{\operatorname{Re}_{1}}{\operatorname{Re}_{2}} \frac{\varphi_{1}}{\varphi_{2}}=R_{\mathrm{Re}} R_{\varphi} . \text { (2) }
$$

Here $\operatorname{Re}_{1}, \mathrm{Re}_{2}$ - values of flow regimes of heat carriers; $\varphi_{1}$, $\varphi_{2}$ - fin factors; $R_{\mathrm{Re}}=\mathrm{Re}_{1} / \mathrm{Re}_{2}$ is the parameter describing the flow regimes ratio for hot and cold heat carriers; $R_{\varphi}=\varphi_{1} / \varphi_{2}$ is the parameter describing the fin's surfaces area ratio at cold and hot sides of heat exchange.

The physical meaning of the $R R$ criterion is "how much the thermal resistance from the cold flow side is greater than thermal resistance from the hot flow side". The values of $\mathrm{Re}_{1}$, $\operatorname{Re}_{2}$ and $\varphi_{1}, \varphi_{2}$, can be set during the initial stage of the design of heat exchanger, that allows us to obtain any required value of $R R$.

In terms of the design of the heat exchanger, the $R_{\mathrm{Re}}$ parameter is responsible for the flow regimes of heat carriers (laminar - turbulent), and the $R_{\varphi}$ parameter is responsible for the geometry of the fins.

\section{B. Two-dimensional Model of a Heat Transfer}

In the series of calculations modification of the developed earlier two-dimensional model of a heat transfer calculation in the compact cross-flow, the plate-fin heat exchanger is carried out $\left(R_{\varphi}\right.$ parameter) (Fig. 3) [9,10].

\section{Heat Transfer Computation in the Hot Section}

The heat transfer and heat balance joint equation for the hot coolant in the grid version takes the form (3):

$$
\begin{aligned}
& \rho_{1 i, j} w_{1 i, j} c_{p f 1 i, j}\left(T_{1 i-1, j}-T_{1 i, j}\right) \Delta x_{1} h_{1}= \\
& \alpha_{1 i, j} \varphi_{1 i, j} \frac{c_{p f 1 i, j}}{c_{p 1}}\left(\bar{T}_{1 i, j}-T_{3 i, j}\right) \Delta x_{1} \Delta x_{2}
\end{aligned}
$$

Here $i$ and $j$ indices are the numbers of the mesh point with respect to the $\mathrm{x}_{1}$ and $\mathrm{x}_{2}$ coordinates, respectively; $h_{1}$ is the finning height; $T_{1}$ and $T_{3}$ are the temperature of hot coolant and walls, respectively; $c_{p \mathrm{f}}$ is the heat-absorbing capacity taking into account phase transformation; $\varphi$ is the finning coefficient which characterizes the fin area per unit of the plate area. For solving the equation, it is necessary to use thermophysical properties of heat carriers, which are 
associated with the heat and mass transfer computation in the coolant, and also take into account the effect of high pressure and temperature of air on the heat transfer from the channel walls [9].
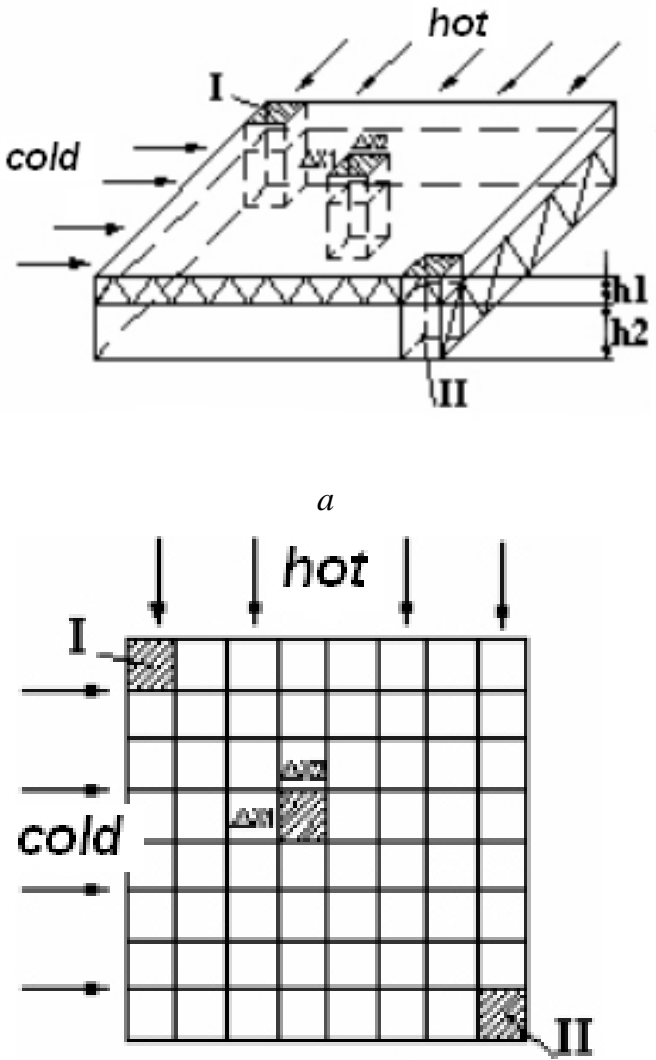

$b$

Fig. 3. A two-dimensional model for the local heat transfer calculation: a calculated element, b - calculated scheme (100 cells), $h_{1}$ - fins package for the hot heat carrier, $h_{2}$ - fins package for the cold heat carrier, $\Delta x_{1} \Delta x_{2}-$ calculated heat-transmitting element, I - first calculated element, II - last calculated element

\section{Heat Transfer Computation in the Cold Section}

The heat transfer and heat balance joint equation for the cold coolant in the grid version takes the form (4):

$$
\begin{aligned}
& \rho_{2 i, j} w_{2 i, j} c_{p f 2 i, j}\left(T_{2 i, j}-T_{2 i, j-1}\right) \Delta x_{2} h_{2}= \\
& \alpha_{2 i, j} \varphi_{2 i, j} \frac{c_{p f 2 i, j}}{c_{p 2}}\left(T_{3 i, j}-\bar{T}_{2 i, j}\right) \Delta x_{1} \Delta x_{2}
\end{aligned}
$$

In the same way as for the hot section, for solving the equation, it is necessary to use thermophysical properties of heat carriers.

\section{E. Heat Transfer Computation Particularities}

In computing the heat transfer rate in the hot and cold sections, the equation as the criterion dependence is used: $\mathrm{Nu}$ $=0.016 \mathrm{Re}^{0,8}$. The equation gives the value of the heat transfer coefficient in the region of the stabilized heat transfer for a particular finning type, used in a heat exchanger-condenser.
In the previously developed heat transfer computation models [9], these grid equations on $10 \times 10 \ldots 40 \times 40$ grids with fixed finning in both sections were solved. The maximum temperatures determination error at $0.01 \ldots 0.001{ }^{\circ} \mathrm{C}$ was set.

\section{F. Modification of Two-dimensional Model}

The modification of the previously developed twodimensional model for calculating heat transfer in a cross-flow compact plate-fin heat exchanger [9] was carried out for calculation. In particular, the another stage in which the original 100x100 grid cells two-dimensional model of the $x$ and $y$ was divided into four equal sections in the direction of movement of hot and cold fluids flow was added into the original algorithm developed before. The maximum temperatures determination error at $0.0001{ }^{\circ} \mathrm{C}$ was set. As a result of the computations, two-dimensional temperature distributions of hot, cold coolants and surface temperatures on a grid of 100x100 cells were determined. Consequently, the heat transfer surface was divided into 16 elementary "heat exchangers" (with a $25 \times 25$ grid of cells), each of which have individual geometric parameters of fins (Fig. 4). This allows you to receive all the necessary options for the relations of thermal resistances in each of the 16 "heat exchangers".

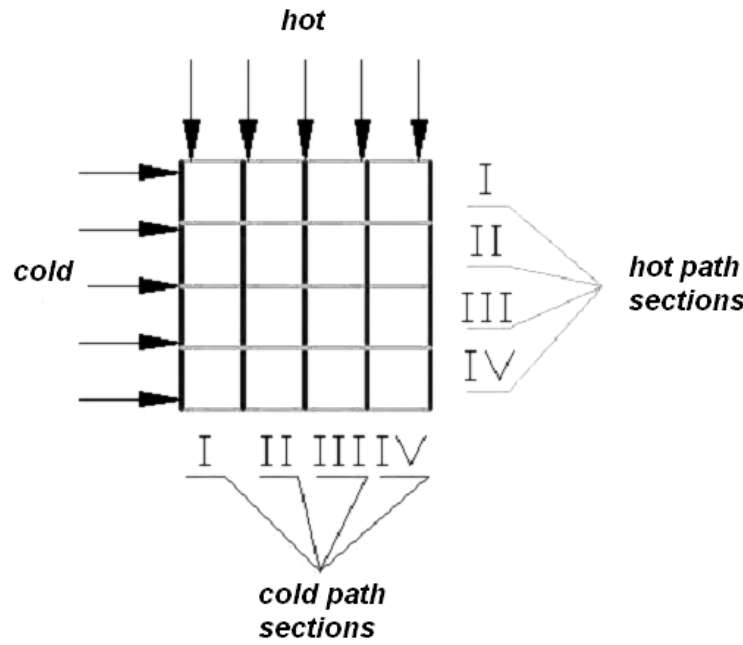

Fig. 4. Sectional separation of the finnings along the tracts

The use of variability of geometric factor $R_{\varphi}$ is allows to change the temperature distribution across the heat transfer surface with a fixed value of flow regime factor $R_{\mathrm{Re}}$.

The reliability of the model verified by comparison with the previous studies: the results are corresponded quantitatively and qualitatively.

The results of series of numerical studies on the effect of variability of $R_{\varphi}$ parameters (geometrical factor) on the twodimensional distribution of temperature fields in a heat exchanger are presented. In particular, variable $R_{\varphi 2}$ - in the cold tract; variable $R_{\varphi 1}$ - in the hot tract; variable $R_{\varphi 1}$ and $R_{\varphi 2}$ in the both tracts have been conducted during the studies. 
Four options of task were considered: 1) the heat exchanger with constant fins geometry in both tracts; 2) the heat exchanger with variable fins geometry in the cold tract; 3 ) the heat exchanger with variable fins geometry in the hot tract; 4) the heat exchanger with variable fins geometry in both tracts. Inlet and outlet parameters of hot and cold heat carriers were the same for all options.

\section{THE RESULTS OF CALCULATIONS}

\section{A. The Heat Exchanger with Constant Fins Geometry in Both Tracts}

The results of the first option correspond to the classical method of calculations for designing with a constant ratio $R R$ $=1$, allowing a heat exchanger with maximum efficiency (Fig. 5). The temperature drop across the heat transfer surface (plate) is $300{ }^{\circ} \mathrm{C}$, which gives the maximum thermal stresses in the design of the heat exchanger.

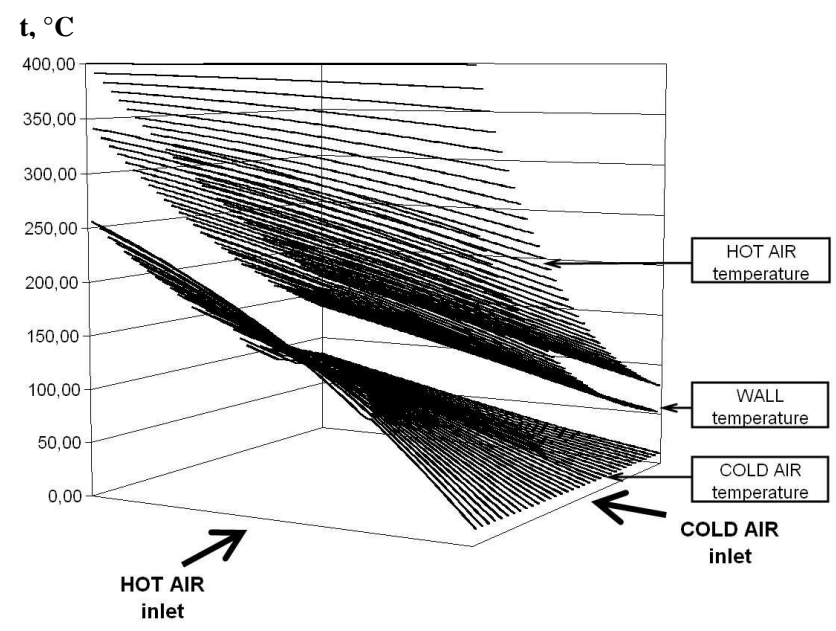

Fig. 5. The heat transfer surface temperature (WALL) and the distribution of the temperature across the hot and cold tracts. Option 1.

\section{B. The Heat Exchanger with Variable Fins Geometry in the Cold or Hot Tract}

The second option is obtained by stepwise changes of the fins in the cold tract of the heat exchanger so that the coefficient of thermal resistance varies from the input to the output of the cold tract. The geometric parameters of the hot fins are constant.

Similarly, the third option was obtained by stepwise changes of fins in the hot flow side so that the ratio of the thermal resistance is variable from input to output of the hot tract.

\section{The Heat Exchanger with Variable Fins Geometry in Both Tracts}

The four different fins in the cold and hot tracts occupying a quarter of the length of each tract were utilized at fourth option. Thus is formed a two-dimensional change in the ratio of thermal resistances across the heat transfer surface. Along the diagonal with a minimum temperature difference the ratio of thermal resistances $R R$ changes from 0.33 to 0.51 , at the same time, along the diagonal with the maximum temperature difference in the direction of "the hot corner" it is reduced to $R R=0.28$, whereas in the direction of "the cold corner", it is increased to $R R=0.59$.

The results of calculation are demonstrated that the change of the thermal resistances ratio $R R$ in the range of $0.2 \ldots 0.6$ allows about 2-time reduction of the temperature difference on the surface of heat exchanger to $150{ }^{\circ} \mathrm{C}$ and significantly reduce the thermal stresses compared to the original approach, based on the desire to ensure the value of the ratio of thermal resistances $R R=1.0$ (Fig. 6).

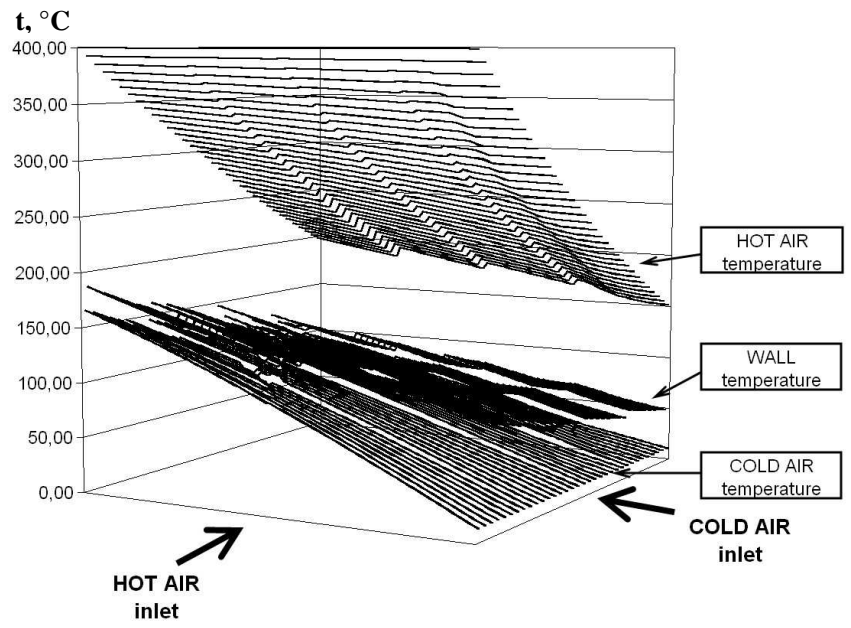

Fig. 6. The heat transfer surface temperature (WALL) and the distribution of the temperature across the hot and cold tracts. Option 4.

\section{Dependence of the maximum temperature of the heat exchange surface on the ratio of thermal resistances for various designs of the primary heat exchange}

Fig. 7 presents the results of comparison of the maximum temperature of the heat exchange surface depending on four variants of the finning geometry over a wide range of the value of the number $R R=0.4 \ldots 1.2$. The option 1 has a maximum temperature in the region of $340 \ldots 350{ }^{\circ} \mathrm{C}$. Option 2 (variable cold finning) was investigated in the range of $R R=0.8 \ldots 1.2$ and has a temperature value in the range of $280 \ldots 320{ }^{\circ} \mathrm{C}$. Option 3 (variable hot finning) was studied in the range of $R R=0.4 \ldots 0.8$ and has a temperature value in the range of $240 \ldots 300{ }^{\circ} \mathrm{C}$. Option 4 (variable both fins) was investigated in the range of $R R=0.6 \ldots 1.08$ and has a temperature value in the range of $230 \ldots 280^{\circ} \mathrm{C}$. As a result of the comparison, the following conclusions can be drawn: 1) for equal $R R$ values, option 1 is the worst, followed by options 2 and 3 , option 4 is the best; 2) regardless of the options, the lower the value of RR, the lower the value of the maximum surface temperatures.

\section{E. The combined effect of geometric and regime factors on the temperature of the heat exchange surface of the primary heat exchanger}

In this series of calculations, the combined effect of geometric and regime factors on the heat transfer surface 
temperature of the primary heat exchanger is investigated. The geometric factor was set in the range of $R_{\varphi}=\varphi_{1} / \varphi_{2}=$ 0.28...0.6. The regime factor was set to a fixed $R_{\mathrm{Re}}=\mathrm{Re}_{1} / \mathrm{Re}_{2}$ $=0.25$. As a result, the combined factor $R R=R_{\mathrm{Re}} R_{\varphi}$ changed in the range of $R R=0.07 \ldots 0.15$. As a result, the minimum surface temperature was $38^{\circ} \mathrm{C}$, the maximum temperature was $105^{\circ} \mathrm{C}$; the temperature difference was $67{ }^{\circ} \mathrm{C}$ (Fig. 8). Thus, the combined use of geometric and regime factors allows one to reduce the maximum temperature from $350{ }^{\circ} \mathrm{C}$ to $105{ }^{\circ} \mathrm{C}$ (more than three times), and the temperature drop from $300{ }^{\circ} \mathrm{C}$ to $67^{\circ} \mathrm{C}$ (4.5 times).

Preliminary estimates have shown that a decrease in the maximum temperature and the temperature difference of the surface allows an increase in the number of thermal loading cycles from 1000 to 4000 [10]. These results are primary and require further study.

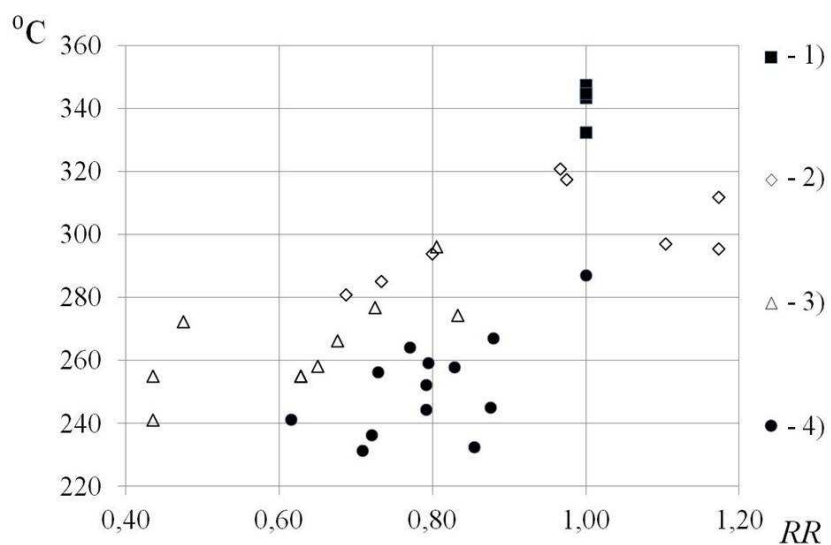

Fig. 7. Dependence of the maximum temperature of the heat exchange surface on the ratio of thermal resistances for various designs of the primary heat exchanger: 1) constant geometry of finning in both tracts; 2) variable geometry of finning in the cold tract; 3 ) variable geometry of finning in the hot tract, 4) variable geometry of finning in both tracts

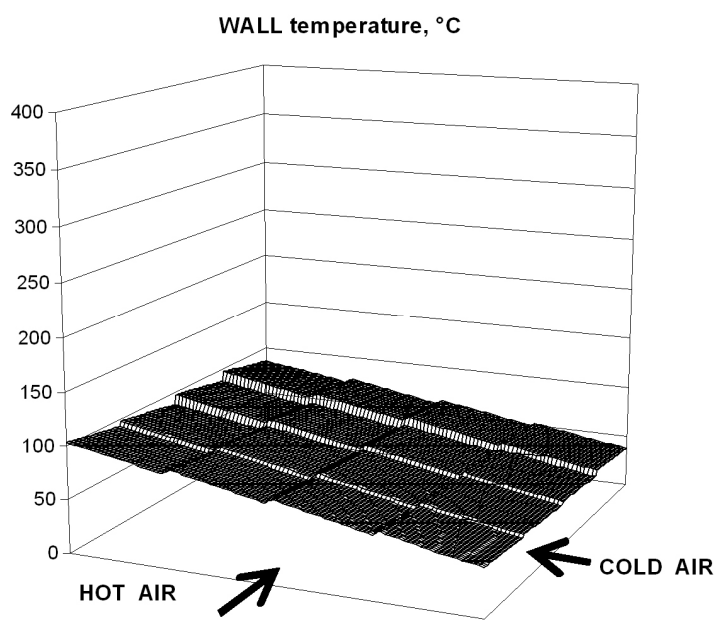

Fig. 8. The combined effect of geometric and regime factors on the temperature of the heat exchange surface of the primary heat exchanger

\section{CONCLUSION}

The temperature field of the heat transfer surface and thermal stresses for different variants of the heat exchanger designs were considered. The study is focused on the search for such optimal temperature distribution across the heat transfer surface (plate), at which the thermal stresses in the heat exchanger is minimum. As a result, research has investigated the effect of the variable ratio of thermal resistance $\mathrm{RR}$ on reducing the temperature difference along the heat transfer surface. The versions of the heat exchanger design with a favorable redistribution of heat transfer surface temperature was created. The optimizing of the finning parameters, the reduction of temperature and thermal stresses in a heat exchanger allows one to extend the life of heat exchangers operating in heat-stressed conditions.

The paper presents the criteria and algorithms for an integrated design optimization of compact plate-fin heat exchangers developed in the course of years of research. The enhanced software package allows defining the design parameters of the heat exchanger in a wide range of flow regime and geometric parameters. The work is of interest to professionals involved in the design of compact plate-fin heat exchangers operating in transitional high-temperature conditions.

\section{References}

[1] C.B. Daletskiy, Formation of Operational and Technical Characteristics of Civil Aircraft. Moscow: Air Transport, 2005, 416 p.

[2] A.P. Gusenkov, G.M. Moskvitin, V.N. Khoroshilov, Low-cycle Strength of Shell Structures. Moscow: Nauka, 1989, 254 p.

[3] V.M. Kais, A.L. London, Compact Heat Exchangers. Moscow: Mechanical Engineering, 1967, 224 p.

[4] G.I. Voronin, Designing of Machines and Units of Air Conditioning Systems. Moscow: Mechanical Engineering, 1978, 554 p.

[5] G.A. Dreitzer, Compact Heat Exchangers: Study Letter. Moscow: MAI, 1986, 74 p.

[6] E.K. Kalinin, G.A. Dreitzer, I.Z. Kopp, A.C. Myakochin Effective Heat Exchange Surfaces. Moscow: Energoatomizdat, 1998, 408 p.

[7] Y.V. Dyachenko, V.A. Sparin, A.V. Chichindaev, Life Support Systems for Aircraft: A Manual for University Students. Novosibirsk: NSTU publishing house. 2003, pp. 307-334, pp.369-406.

[8] N.V. Antonova, L.D. Dubrovin, E.E. Egorov, A.K. Kalliopinin, Y.M. Petrov, V.V. Rujitskay, K.I. Starostin, A.V. Chichindaev, Y.M. Shustrov, Designing of Aviation Air Conditioning Systems: A Manual for University Students, Edited by Y.M. Shustrova. Moscow: Mashinostroenie, 2006, pp. 23-40, pp. 357-365.

[9] A.V. Chichindaev, Compact Plate-Fin Heat Exchangers Optimization. Theoretical Foundations: the Manual for University Students, 2nd ed. Novosibirsk: NSTU Publ., 2017, pp. 17-180, pp. 263-296, pp. 339-368.

[10] I.G. Diomidov, Influence Investigation of the Thermal Resistances Variable Ratio on the Temperature Distribution in a Compact Plate-Fin Heat Exchanger: Extended Abstract of Cand. Sci. Novosibirsk: NSTU publishing house, 2013, $22 \mathrm{p}$. 